\title{
Compound fault rupture during the 2004 off the Kii Peninsula earthquake ( $M$ 7.4) inferred from highly resolved coseismic sea-surface deformation
}

\author{
Toshitaka Baba ${ }^{1}$, Phil. R. Cummins ${ }^{2}$, and Takane Hori ${ }^{1}$ \\ ${ }^{1}$ Institute for Research on Earth Evolution, Japan Agency for Marine-Earth Science and Technology, 3173-25 Showa-machi, \\ Kanazawa-ku, Yokohama 236-0001, Japan \\ ${ }^{2}$ Minerals and Geohazards Division, Geoscience Australia, GPO Box 378, Canberra, ACT 2601 Australia
}

(Received November 30, 2004; Revised February 24, 2005; Accepted February 25, 2005)

\begin{abstract}
For a tsunami inversion analysis, we incorporated a new technique that uses many Green's functions to improve model spatial resolution. Since this method precisely reproduces observed tsunami waveforms, we can obtain a better model of the tsunami source process. We applied the proposed method to the 2004 off the Kii Peninsula earthquake to determine what fault or faults ruptured to cause the earthquake. The estimated coseismic seasurface deformation extended to two directions, and it was consistent with the distributions of the two aftershock swarms. Hence, we concluded that the earthquake resulted from the rupture of two faults.
\end{abstract}

Key words: The 2004 off the Kii peninsula earthquake, compound rupture, cosesimic sea-surface deformation, tsunami inversion, high-resolution.

\section{Introduction}

A large earthquake of $M 7.4$ occurred off Kii Peninsula, southwest Japan, at 23:57 (Japan Standard Time) on September 05, 2004 (hereafter, the 2004 off the Kii Peninsula earthquake; Fig. 1). The earthquake was accompanied by a significant foreshock $(M 6.9)$ and aftershock $(M$ 6.4). The focal mechanism of the 2004 off the Kii peninsula earthquake determined by the Japan Meteorological Agency (JMA) indicated high-angle thrust faulting with north-south compression (Fig. 1). Therefore, the earthquake was assumed to be an intraplate event. This earthquake also caused a moderate tsunami, which was observed by tide gauges along the southern coast of Japan and by three offshore tsunami gauges off Cape Muroto, a GPS tsunami gauge (hereafter, GPS-TG; Kato et al., 2000), and two cabled ocean-bottom pressure gauges (hereafter, PG1 and PG2; Monma et al., 1997; Matsumoto and Mikada, 2005).

Figure 1 also shows the aftershock distribution during the two weeks following the main shock. The aftershock distribution has two axes, one parallel to the trough axis, and the other extending to the northwest. The aftershocks in the northwestward-extending swarm had mainly strike-slip focal mechanisms (Ito et al., 2005), which were clearly different from the focal mechanism of the main shock. The predominant focal mechanism of the aftershock swarm along the trough axis, on the other hand, was similar to that of the main shock (Ito et al., 2005). One possible interpretation of the aftershock swarm distributed to the northwest is that the seismic activity was triggered by stress changes caused by the main shock. Alternatively, rupture during the

Copy right(c) The Society of Geomagnetism and Earth, Planetary and Space Sciences (SGEPSS); The Seismological Society of Japan; The Volcanological Society of Japan; The Geodetic Society of Japan; The Japanese Society for Planetary Sciences; TERRAPUB main shock might have involved some strike-slip motion along a northwest-trending fault, accompanying a presumably larger thrust slip along a fault parallel to the trough axis. This fundamental question about the mechanism of the 2004 off the Kii peninsula earthquake is still unresolved.

In order to answer such questions, inversion analyses using seismic, tsunami, and geodetic data are useful (e.g., see respectively Kikuchi and Kanamori, 1991; Satake, 1987; Yabuki and Matsu'ura, 1992). However, such analyses typically rely on an a priori assumption of the correct fault plane. The complicated aftershock distribution of the 2004 off the Kii peninsula earthquake makes it difficult to determine the correct fault plane unambiguously, especially since the depths of the offshore aftershocks were poorly determined by the land-based seismographic network. Such ambiguity often complicated the analysis of subductionzone earthquakes, such as the 1994 Shikotan earthquake, for which Kikuchi and Kanamori (1995) chose a fault plane conjugate to that assumed by Tanioka et al. (1995), or the 1998 Papua New Guinea earthquake, which Geist (2000) suggested may have occurred on a steeply dipping normal fault rather than on the shallow thrust fault assumed by Kikuchi et al. (1999).

Hence, we use a seldom-used tsunami inversion method (Aida, 1972) that does not require the a priori assumption of a fault plane. The method, explained in detail below, estimates sea-surface deformation immediately after the main shock rather than slip on a fault plane as is more common (Satake, 1987). Tsunami studies with the methods of Aida (1972) or Satake (1987) have used only a few Green's functions, but a large number of Green's functions should increase the spatial resolution of the source model. In this study, a new technique which handles many Green's functions is also incorporated into the tsunami inversion scheme. We apply this improved method to the 2004 off the Kii 


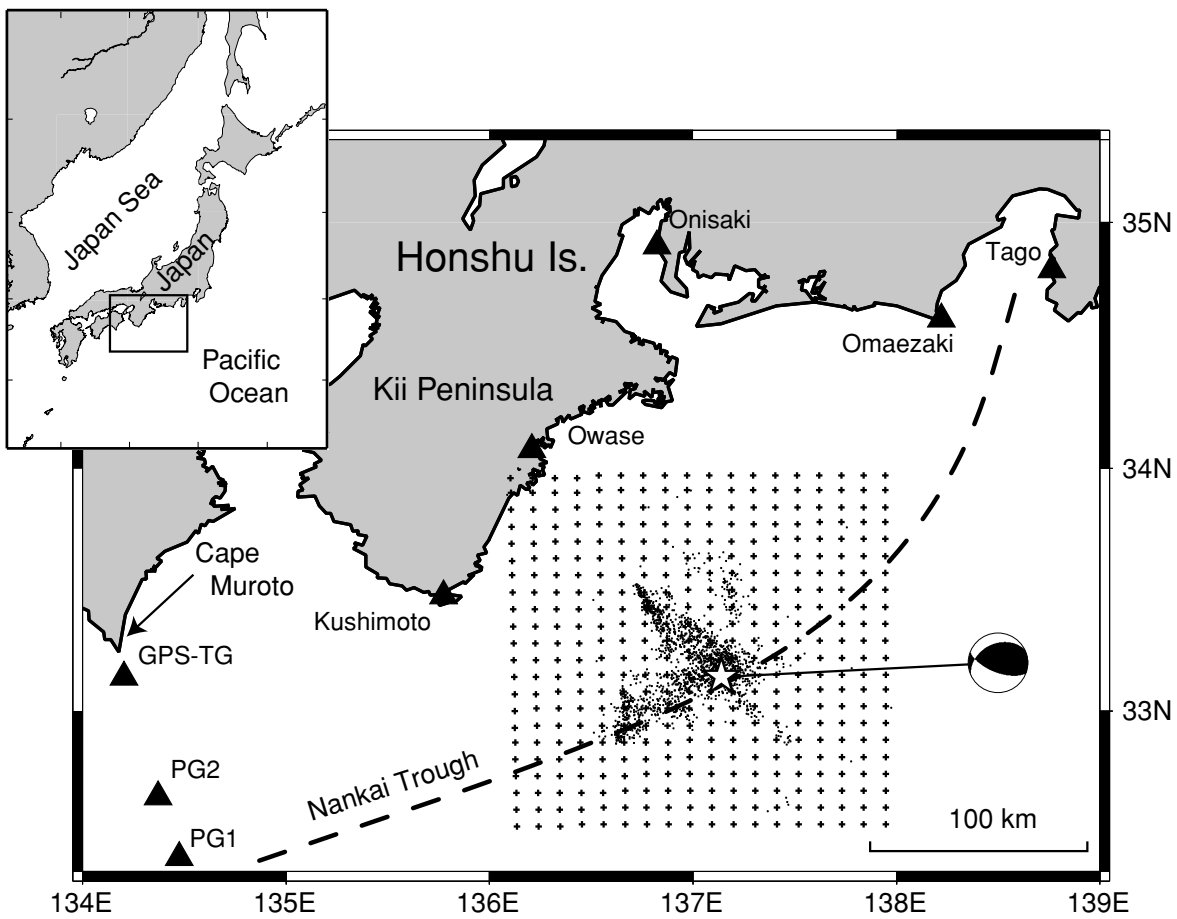

Fig. 1. Computation area for the tsunami caused by the 2004 off the Kii peninsula earthquake. Crosses indicate locations of centers of distributed basis functions. The star shows the hypocenter of the 2004 off the Kii peninsula earthquake, and the dots show hypocenters of aftershocks occurring in the following two weeks as determined by the JMA. The focal mechanism of the main shock as estimated by the JMA is also shown. Triangles denote tide gauge stations with station names, the GPS tsunami gauge (GPS-TG), and ocean-bottom pressure gauges (PG1 and PG2).

peninsula earthquake, and discuss how this information can be used to determine which fault plane or planes ruptured during the earthquake.

\section{Method and Data}

Tsunamis generally occur as follows (Fig. 2): step 1, slip on a fault plane or a submarine slump causes vertical displacement of the seafloor; step 2, vertical displacement of the seafloor displaces seawater vertically; step 3, the seasurface simultaneously rises or subsides; step 4, the displaced sea surface spreads horizontally as a tsunami; and step 5, tsunami waveforms are finally recorded at observation stations. In the usual tsunami inversion method (Satake, 1987), the tsunami waveforms are inverted directly to obtain the slip on a fault plane (white arrows in Fig. 2). The difference between the usual tsunami inversion method and the method presented here is that we now stop inverting tsunami waveforms at the sea-surface displacement step (black arrows in Fig. 2). Thus, while the Green's functions used to relate the model to observations in the method of Satake (1987) include both the effects of fault displacement on sea-surface deformation as well as those of tsunami propagation, the Green's functions used in our study describe only tsunami propagation.

We here note that the method for sea-surface deformation does not require defining a fault plane because the inversion determines sea-surface deformation, not slip on a fault. Offshore fault configuration is generally not clear because the depths of aftershocks cannot be determined with certainty by only land-based stations. Hence, the main advantage of this method is that it does not require the a priori assump- tion of a fault plane. If we are forced to estimate slip distribution using the usual method (Satake, 1987), based on only a rough guess of the fault plane, a large uncertainty will remain in the solution. Furthermore, the usual method cannot cope with a tsunami caused by a submarine slump (e.g., Tappin et al., 2001). With the method used in this study, on the other hand, we can accurately estimate the coseismic sea-surface deformation of any tsunami, and then infer the tsunami source mechanism based on the estimated sea-surface deformation.

We use numerous Green's functions calculated from densely distributed sea-surface displacement basis functions, which should accurately reproduce observed tsunami waveforms. However, a large number of Green's functions generally leads to instability in the solution. To avoid this instability, a smoothness constraint on the sea-surface deformation is imposed, as follows:

$$
0=x_{i-1, j}+x_{i+1, j}+x_{i, j-1}+x_{i, j+1}-4 x_{i, j},
$$

where $x_{i j}$ is the coefficient of the local sea-surface displacement basis function centered at position $i$ along the eastwest axis and $j$ along the north-south axis, as indicated in Fig. 1. This can be also written in a vector form as

$$
\mathbf{0}=\mathbf{S x}
$$

where $\mathbf{S}$ is a matrix representing the smoothness constraint and $\mathbf{x}$ is a vector of the coefficients for a set of local basis functions. The smoothness matrix is incorporated into the observational equation by weighting it with a smoothness parameter $(\alpha)$,

$$
\left(\begin{array}{c}
\mathbf{d} \\
\mathbf{0}
\end{array}\right)=\left(\begin{array}{c}
\mathbf{A} \\
\alpha \mathbf{S}
\end{array}\right) \mathbf{x}
$$




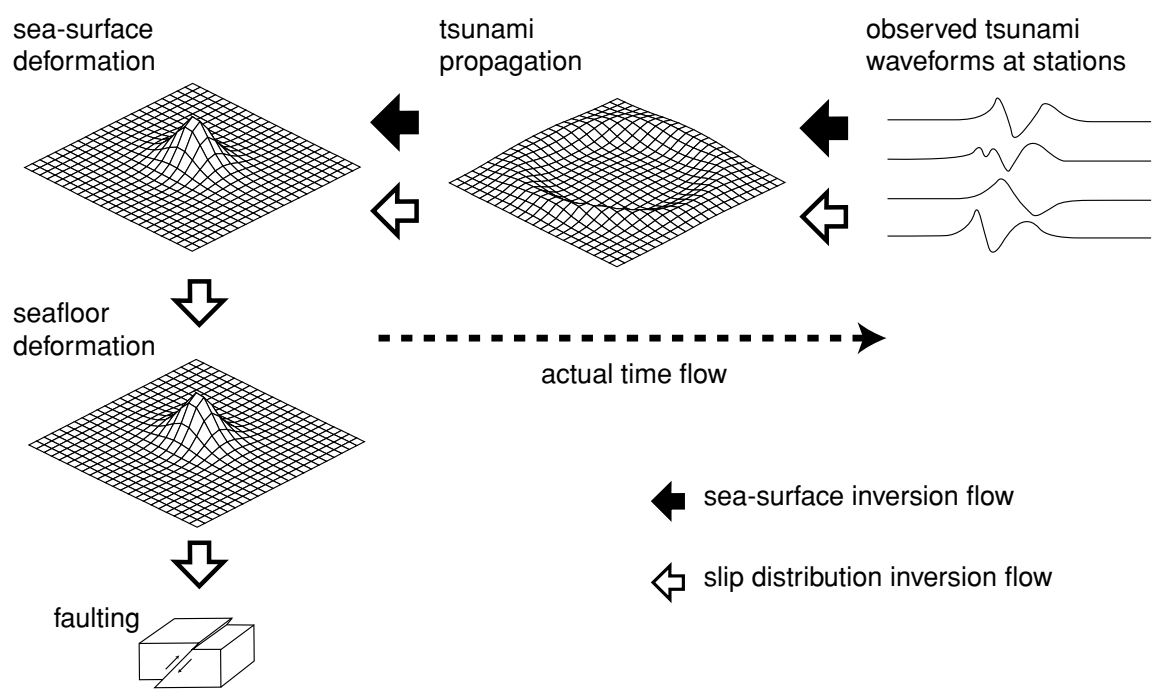

Fig. 2. Schematic illustration of tsunami waveform inversion. White arrows indicate that the general method processing for slip distribution. (b) Black arrows are the flow of the method used in this study for estimating coseismic sea-surface deformation.

where $\mathbf{d}$ is a vector of the observed tsunami waveforms, and $\mathbf{A}$ is a matrix in which each column contains Green's functions describing the tsunami predicted at the observation sites from the sea-surface displacement associated with a unit basis function. We repeatedly invert tsunami waveforms using the least squares method to solve equation (3) for various values of $\alpha$, and choose the smallest $\alpha$ for which the sea-surface deformation obtained in the inversion satisfies the assumption inherent in the long-wave theory used to calculate the Green's functions: that is, that the characteristic wavelength of the seafloor displacement is longer than 20 times the water depth. Finally, the coseismic sea-surface deformation (h) is obtained by

$$
\mathbf{h}=\mathbf{B} \mathbf{x},
$$

where $\mathbf{B}$ is a matrix of the sea-surface displacement basis functions.

The improved method developed in this study was applied to the 2004 off the Kii peninsula earthquake to investigate its source process. Here, considering the tsunami generation mechanism, we used as the sea-surface displacement basis function a shape (Fig. 3) identical to a vertical deformation due to a 1-m slip on a fault, based on linear elastic theory (Okada, 1985). The fault parameters were as follows: strike, $270^{\circ}$; dip, $40^{\circ}$; rake, $90^{\circ}$; width and length, $10 \mathrm{~km}$ each; and shallowest depth, $15 \mathrm{~km}$. We densely distributed 396 basis functions on the sea surface as shown in Fig. 1. This number of basis functions is much larger than that used in other tsunami inversion studies; for example, Aida (1972) and Satake et al. (2005) used 9 and 16 basis functions, respectively. The Green functions for the stations were computed for each distributed basis function. The finite difference computations for the linear long wave equation were carried out by the method of Satake (2002) for the region shown in Fig. 1 . The grid size was $20^{\prime \prime} \times 20^{\prime \prime}$ of latitude and longitude (about $600 \mathrm{~m}$ ). The rise time of the sea-surface displacement basis function was assumed to be $40 \mathrm{~s}$ with constant deformation rate. In the computation,

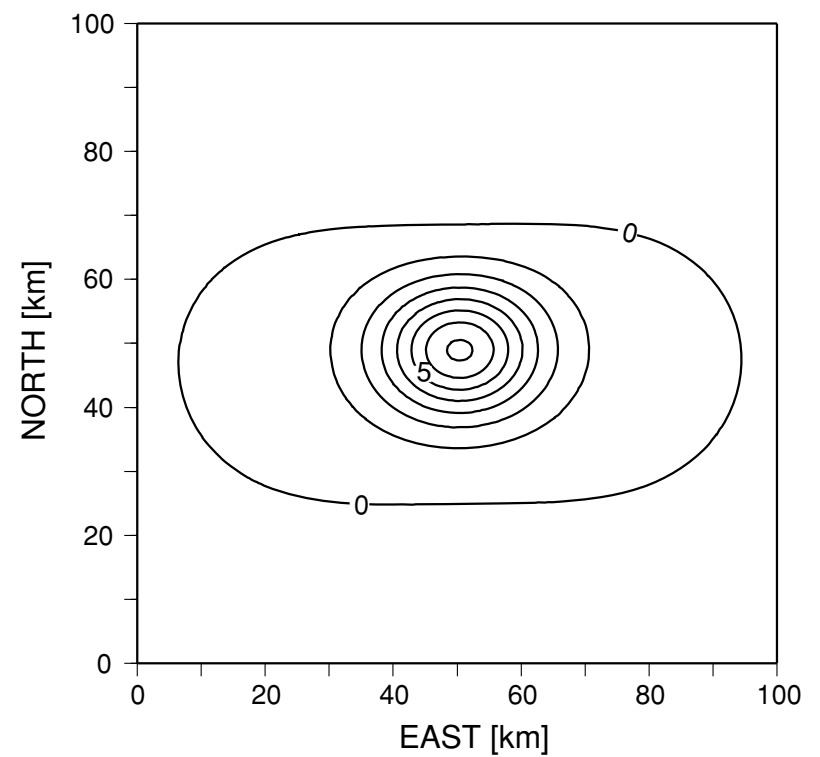

Fig. 3. The local sea-surface deformation basis function used in this study. All contours are for uplift, and the contour interval is $1 \mathrm{~cm}$.

we used a time step of $1.5 \mathrm{~s}$ in order to satisfy the stability condition of the finite difference algorithm.

We used tsunami waveform data recorded at 5 tide gauge stations (Kushimoto, Owase, Onisaki, Omaezaki, and Tago) and 3 offshore tsunami gauges (GPS-TG, PG1, and PG2). GPS-TG is a buoy floating on the sea $13 \mathrm{~km}$ off Cape Muroto that records real-time kinematic Global Positioning System (GPS) data (Kato et al., 2000). PG1 and PG2 are ocean-bottom pressure gauges deployed at depths of about 2300 and $1500 \mathrm{~m}, 100$ and $70 \mathrm{~km}$ off Cape Muroto, respectively. The long-period component, primarily oceanic tidal signals, was removed by applying a block-mean filter with a width of $30 \mathrm{~min}$ to the original records. For the PG station data, short-period components such as hydro-pressure vibrations from seismic Rayleigh waves were also removed by applying a block-mean filter with a width of $1 \mathrm{~min}$. Af- 
(a)

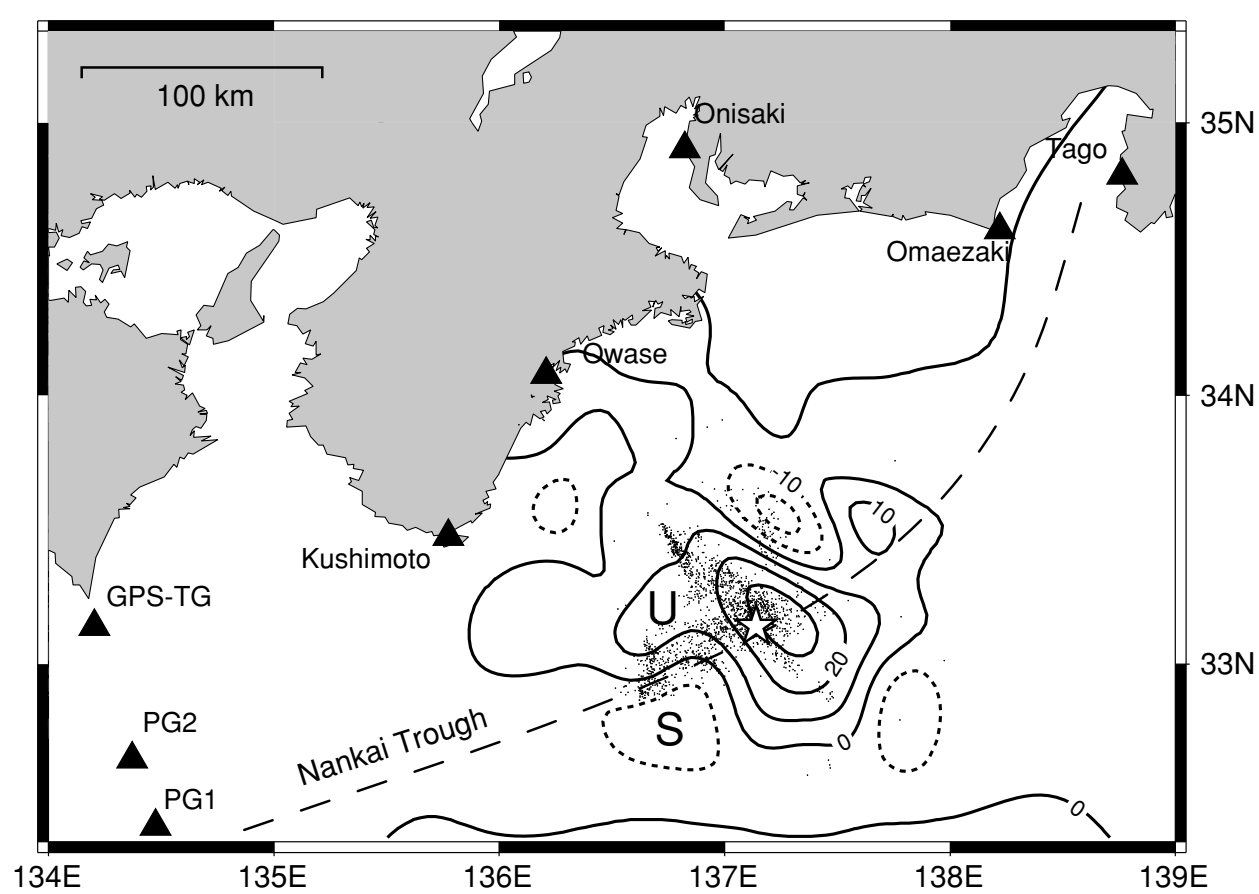

(b)

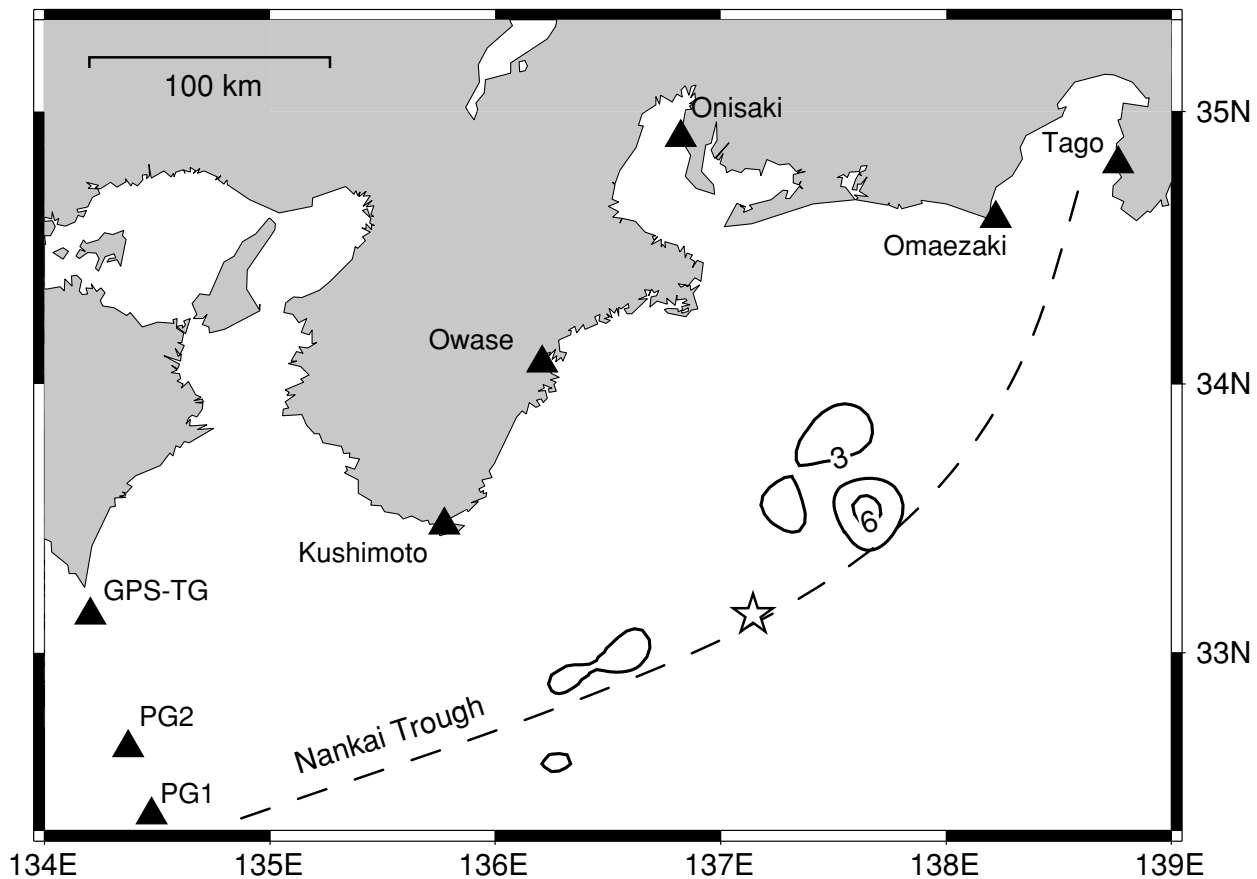

Fig. 4. (a) Estimated coseismic sea-surface deformation of the 2004 off the Kii peninsula earthquake and of the aftershocks occurring within two weeks as determined by the JMA (dots). Solid and dashed contours show uplift and subsidence, respectively. The contour interval is $10 \mathrm{~cm}$. The star shows the hypocenter of the earthquake as determined by the JMA. Triangles denote tide gauge stations, the GPS tsunami gauge, and ocean-bottom pressure gauges. See text for the explanations of "U" and "S". (b) Estimated standard deviation error determined with a Monte Carlo method. The contour interval is $3 \mathrm{~cm}$. The star shows the hypocenter of the 2004 off the Kii peninsula earthquake. 

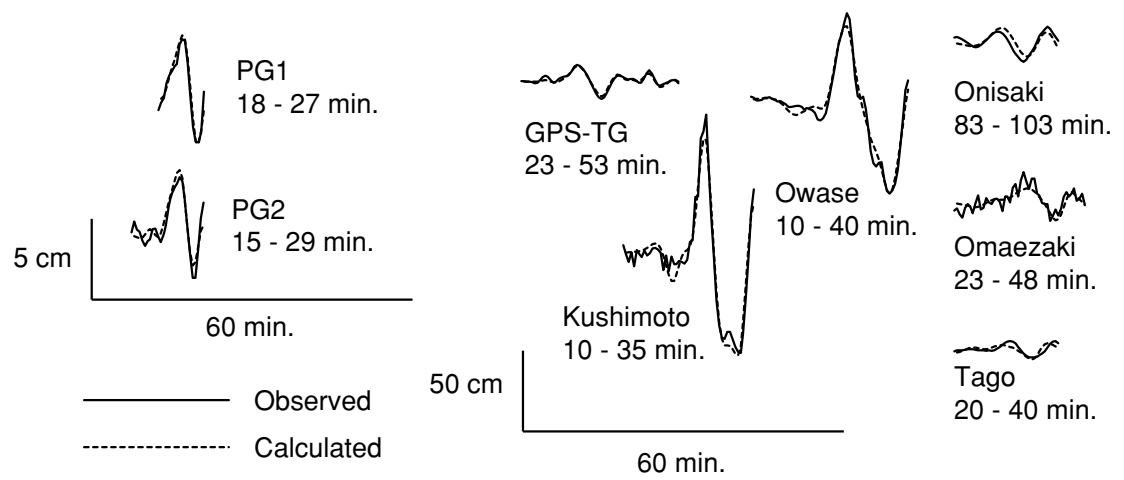

Fig. 5. Comparison of observed (solid line) and calculated (dashed line) tsunami waveforms. Numbers below the station names indicate the time (in minutes) after the earthquake origin time.

ter removing the long- and short-period components, we resampled the data with a sampling interval of $30 \mathrm{~s}$.

The offshore amplitude of a tsunami is normally smaller than its coastal amplitude. The tsunami amplitudes recorded by GPS-TG and the PG stations were about onefifth and one-tenth, respectively, of that recorded by the nearest coastal tide gauge station. However, the offshore tsunami waveforms contain more direct information on the source than those at coastal tide gauges because they are not influenced by complex effects due to the variation of nearshore ocean depths such as reflection and refraction. Therefore, we should give the GPS-TG and PG data used in the tsunami waveform inversion more weight because the offshore data have more significance than the tide gauge data. We therefore used a weighting factor of 5 for the GPSTG data and 10 for the PG station data in the inversion, after the analysis of Tanioka et al. (2004). Finally, the length of the data vector (d) was 346 in this inversion scheme which was shorter than the length of the model parameter vector (396). But the additional matrix which represents the smoothing criterion (S) made it possible to solve Eq. (3).

For error analysis, we used a Monte Carlo method. We calculated theoretical tsunami waveforms at the observation stations from the estimated sea-surface deformation and added Gaussian random noise with standard deviations of $1,0.2$, and $0.1 \mathrm{~cm}$ on the tide gauges, GPS-TG, and pressure gauges, respectively. The theoretical tsunami waveforms with the added noise were treated as observations and inverted to estimate the corresponding sea-surface deformation. We repeated this procedure 100 times to estimate deviations from the original inversion result.

\section{Coseismic Sea-surface Deformation of the 2004 off the Kii peninsula Earthquake}

The estimated coseismic sea-surface deformation and standard deviation error are shown in Fig. 4. The maximum uplift of about $35 \mathrm{~cm}$ is located near the main shock hypocenter. The area of maximum subsidence, $25 \mathrm{~cm}$, is located northeast of the maximum uplift area. To the east of the subsidence area is an area uplifted about $10 \mathrm{~cm}$, but this image is doubtful because of a large estimated error (Fig. 4(b)). The pattern of uplift extends mainly to the northwest. In addition, an uplifted area extends along the trough axis to the west of the hypocenter (U in Fig. 4(a)).
South of the uplifted area, an area with a subsidence of 10 $\mathrm{cm}$ is also imaged ( $\mathrm{S}$ in Fig. 4(a)). The observed and computed tsunami waveforms are compared in Fig. 5. The time windows used in the inversion are also shown in this figure. The computed tsunami waveforms match well the observed tsunami waveforms. The variance reduction for the inversion is $95 \%$.

The sea-surface deformation of the 2004 off the Kii peninsula earthquake was also estimated by Satake et al. (2005). They used 16 basis functions with a different data set consisting of 15 stations. The different station set partly includes the same stations we inverted. Although the different set s may not allow us to directly compare the results of their study with ours, our agreement between computed tsunami waveforms and observed ones at the common stations is much better than that of Satake et al. (2005). We believe this is because of the large number (396) of basis functions in our study.

\section{Discussion}

The aim of this study was to reveal the source mechanism of the 2004 off the Kii peninsula earthquake. This was due to occurring of two aftershock swarms following the earthquake. The predominant focal mechanism of one swarm was consisted with the focal mechanism of the main shock, but the other was not (Fig. 4(a)). The latter aftershock swarm might be a triggered activity due to the stress change caused by the main shock, or alternatively, the latter swarm may be a response to fault motion subsidiary to that which occurred on the main fault plane during the 2004 off the Kii peninsula earthquake. As shown in Fig. 4(a), the estimated sea-surface deformation extended to two directions which were in agreement with the directions of the two aftershock swarms. Our result indicated that two faults oriented parallel to the aftershock swarms ruptured simultaneously at the main shock. This compound fault model might be also supported by on-land GPS analysis of Hashimoto et al. (2005), although their model was estimated from a sum of crustal displacements due to the earthquake sequence that consists of the off the Kii peninsula earthquake, its foreshock and aftershock.

Finally, we would like to discuss an advantageous of the new technique which uses many small basis functions. The shallow-water theory used in the tsunami calculation 
is valid when the tsunami wavelength is much longer than the water depth. Conversely, the theory limits the shape of estimated sea-surface deformation which can be accurately inferred in the inversion to those involving smooth no short-wavelength changes in seafloor topography. Previous methods have ensured compliance with the shallowwater theory by using large basis functions that generate only long-wavelength sea-surface deformation. However, their resolution of details of the sea-surface deformation was not always optimum; for example, peaks and troughs in the sea-surface deformation were spread out by large basis functions, even when the data and theory might allow for finer resolution. In the method developed here, use of many small basis functions with a smoothing criterion optimized the resolution of the sea-surface deformation while maintaining a smooth combination of basis functions that is consist with the shallow-water theory. Although each basis function might be too small to be consistent with shallowwater theory, linearity of the shallow-water wave equations allowed these solutions to be superposed to produce a solution that was consistent with shallow-water theory.

\section{Conclusions}

A new technique which uses a large number of Green's functions was included in the tsunami inversion scheme. The technique developed allows recovery of optimal spatial resolution in the sea-surface deformation that is consistent with the shallow water theory. The coseismic sea-surface deformation of the 2004 off the Kii peninsula earthquake obtained by the improved method extended in two directions, consistent with the bi-directional directions distribution of aftershocks. We therefore conclude that the 2004 off the Kii peninsula earthquake resulted from the simultaneous rupture of two faults.

Acknowledgments. We thank the Japan Meteorological Agency, the Geophysical Survey Institute, and Y. Terada for providing us with the digital data. Suggestions by H. Sakaguchi and A. Smith were very useful for improving this manuscript. Reviews by J. Townend and K. Satake are greatly appreciated. We used generic mapping tools (Wessel and Smith, 1995) to make the figures in this paper and we used code developed by K. Satake to calculate the tsunami propagation.

\section{References}

Aida, I., Numerical estimation of a tsunami source, Zisin (J. Seism. Soc. Jpn.) ser 2, 25, 343-352, 1972.
Geist, E. L., Origin of the 17 July 1998 Papua New Guinea tsunami: earthquake or landslide?, Seism. Res. Lett., 71, 344-351, 2000.

Hashimoto, M., K. Onoue, F. Ohya, Y. Hoso, K. Segawa, K. Sato, and Y. Fujita, Crustal deformations in Kii peninsula associated with the SE off the Kii peninsula earthquake sequence of September 5, 2004 derived from dense GPS observations, Earth Planets Space, 57, this issue, 185190, 2005.

Ito, Y., T. Matsumoto, H. Kimura, H. Matsubayashi, K. Obara, and S. Sekiguchi, Spatial distribution of centroid moment tensors for 2004 southeastern Off-Kii Peninsula Earthquakes, Earth Planets Space, 2005 (submitted).

Kato, T., Y. Terada, M. Kinoshita, H. Kakimoto, H. Isshiki, M. Matsuishi, A. Yokoyama, and T. Tanno, Real-time observation of tsunami by RTKGPS, Earth Planets Space, 52, 841-845, 2000.

Kikuchi, M. and H. Kanamori, Inversion of complex body wave-III, Bull. Seism. Soc. Am., 81, 2335-2350, 1991.

Kikuchi, M. and H. Kanamori, The Shikotan earthquake of October 4, 1994: lithospheric earthquake, Geophys. Res. Lett., 22, 1661-1664, 1995.

Kikuchi, M., Y. Yamanaka, K. Abe, and Y. Morita, Source rupture process of the Papua New Guinea earthquake of July 17, 1998 inferred from teleseismic body waves, Earth Planets Space, 51, 1319-1324, 1999.

Matsumoto, H. and H. Mikada, Fault geometry of the 2004 off the Kii peninsula earthquake inferred from offshore pressure waveforms, Earth Planets Space, 57, this issue, 161-166, 2005.

Monma, H., N. Fujiwara, R. Iwase, K. Kawaguchi, S. Suzuki, and H. Kinoshita, Monitoring system for submarine earthquakes and deep sea environment, Proc. MTS/IEEE OCEANS'97, 2, 1453-1459, 1997.

Okada, Y., Surface deformation due to shear and tensile faults in a halfspace, Bull. Seism. Soc. Am., 75, 1135-1154, 1985.

Satake, K., Inversion of tsunami waveforms for the estimation of a fault heterogeneity: method and numerical experiments, J. Phys. Earth, 35, 241-254, 1987.

Satake, K., Tsunamis, in International Handbook of Earthquake and Engineering Seismology, 81A, 437-451, IASPEI, 2002.

Satake, K., T. Baba, K. Hirata, S. Iwasaki, T. Kato, S. Koshimura, J. Takenaka, and Y. Terada, Tsunami source of the 2004 off the Kii Peninsula earthquakes inferred from offshore tsunami and coastal tide gauges, Earth Planets Space, 57, this issue, 173-178, 2005.

Tanioka, Y., L. Rarry, and K. Satake, The great Kurile earthquake of October 4, 1994, tore the slab, Geophys. Res. Lett., 22, 1661-1664, 1995.

Tanioka, Y., K. Hirata, R. Hino, and T. Kanazawa, Slip distribution of the 2003 Tokachi-oki earthquake estimated from tsunami waveform inversion, Earth Planets Space, 56, 373-376, 2004.

Tappin, D. R., P. Watts, G. M. McMurtry, Y. Lafoy, and T. Matsumoto, The Sissano, Papua New Guinea tsunami of July 1998-offshore evidence on the source mechanism, Mar. Geol., 175, 1-23, 2001.

Wessel, P. and W. H. F. Smith, New version generic mapping tools (GMT) version 3.0 released, Eos Trans. AGU, 76, 329, 1995.

Yabuki, T. and M. Matsu'ura, Geodetic data inversion using a Bayesian information criterion for spatial distribution of fault slip, Geophys. $J$. Int., 109, 363-375, 1992.

T. Baba (e-mail: babat@jamstec.go.jp), P. R. Cummins, and T. Hori 